\title{
The Impact of the Weight Status on Cardiovascular Parameters Related to Physical Effort in Young Athletes
}

\author{
Gabriele Mascherini ${ }^{1, *(\mathbb{D}}$, Cristian Petri $^{1}{ }^{1}$, Laura Stefani $^{1}{ }^{1}$, Loira Toncelli $^{1}$, Vittorio Bini ${ }^{2}$, \\ Piergiuseppe Calà ${ }^{3}$ and Giorgio Galanti ${ }^{1}$ (D) \\ 1 Department of Experimental and Clinical Medicine, University of Florence, 50134 Florence, Italy; \\ cristian.petri@unifi.it (C.P.); laura.stefani@unifi.it (L.S.); loira.toncelli@unifi.it (L.T.); \\ giorgio.galanti@unifi.it (G.G.) \\ 2 Dipartimento di Medicina, Università di Perugia, 06156 Perugia, Italy; vittorio.bini@unipg.it \\ 3 Sector "Health and safety in the workplace and special processes in the field of prevention", Directorate of \\ Citizenship Rights and Social Cohesion, Tuscany Region, 50139 Florence, Italy; \\ piergiuseppe.cala@regione.toscana.it \\ * Correspondence: gabriele.mascherini@unifi.it; Tel.: +39-339-689-5925
}

Received: 26 April 2020; Accepted: 7 May 2020; Published: 12 May 2020

check for updates

\begin{abstract}
Excess weight leads to an impaired cardiovascular response to physical exertion even at a young age. Sports training during youth promotes cardiovascular adaptations. The aim of the study is to verify the impact of weight status on cardiovascular parameters related to physical effort in young people who engage in competitive sports. A retrospective study was conducted on 8307 young athletes (5578 males and 2729 females) aged 6-18 years (mean age $13.9 \pm 2.2$ years). The data concerning graded exercise tests of young athletes in normal weight and overweight were compared. Approximately, 13.4\% of the sample had excess weight. Young overweight athletes show a higher resting heart rate as well as systolic and diastolic pressure than young normal weight athletes. Excess weight condition leads to a reduction in the duration of the graded exercise test, reaching higher blood pressure values at the end of the test compared to those with normal weight. After four min from the end of the test, heart rate and systolic/diastolic blood pressure remained higher in the young overweight athletes. Excess weight affects cardiovascular parameters both at rest and in response to physical exertion during youth; however, competitive sport seems to be able to keep these parameters within the normal range even in young overweight athletes.
\end{abstract}

Keywords: youth; overweight; competitive sport; exercise test; obese; heart rate; incremental test; blood pressure

\section{Introduction}

The prevalence of obesity in children and adolescents is a current public health problem [1]. Excess weight involves both metabolic and hemodynamic alterations [2]. The main hemodynamic changes in obese youth are an increase in resting blood pressure and resting heart rate and an increase in peak heart rate during exercise tests compared to lean controls [3].

Cardiovascular parameters related to physical effort are generally assessed through the graded exercise test (GXT) which currently is widely used for detection of coronary artery disease, prediction of cardiovascular events, and evaluation of physical capacity [4]. In normal subjects, during exercise there is an increase in muscle work, which leads to an increase in oxygen demand. To meet these growing requirements, the cardiovascular system applies a gradual rise in cardiac output. [5]. 
During GXT, heart rate (HR) and arterial blood pressure (BP) are the main parameters monitored. Dynamic exercise involves an HR increase linear with workload and oxygen demand [6]. The speed in reduction of HR after termination of the GXT, termed HR recovery, currently is considered as an index of cardiorespiratory fitness and is associated with mortality risk [7].

In addition for BP, dynamic exercise induces a systolic blood pressure (SBP) increase because of increasing cardiac output, whereas diastolic blood pressure (DBP) remains the same or slightly reduced due to peripheral vasodilatation [8]. After exercise, the decrease of cardiac output produces a decline in systolic blood pressure, usually reaching resting levels within six min [9].

The interpretation of GXT data in pediatric subjects requires special considerations; these results may have different connotations based on the age, size, and sex of the child [10]. The impact of body weight is well established on HR response to exercise in children, particularly during an incremental test, the increase in peripheral oxygen demand increases the HR in direct proportion to body weight [11]. Similarly, age and body mass index (BMI) are related to exercise duration in both boys and girls; age has a direct correlation, while BMI has an inverse relationship [12].

However, the influence of BMI on the recovery process after maximal exercise test, measured with HR recovery, is not clear $[7,12,13]$. Maximal BP response to exercise in children appear mostly influenced by age and sex [14]. Systolic BP decreased about $10 \%$ four min after the end of the test in both sexes from 6 to 11 years [15,16]; this recovery process appear to be influenced by excess body weight in non-athletic children [17]. Currently the influence of body weight on cardiovascular performance in young people has been studied mainly on small samples sizes [11], in non-athletic subjects [13] and using different protocols. In addition, most studies with a large sample size did not examine the role of weight status on cardiovascular response to exercise [12,14-16].

Young people who engage in competitive sports have improvements in physical performance and a better cardiovascular response to effort than non-sports peers [18]. While sports appear to play a role in reducing the prevalence of youth obesity [19], it is unclear whether it also has a protective role for cardiovascular parameters related to physical exertion.

Therefore, the purpose of the study is to verify the impact of weight status on the cardiovascular parameters before, during, and after a graded exercise test in a large population of young athletes.

\section{Materials and Methods}

Since 1982, all children in Italy have undergone pre-participation screening to obtain eligibility for competitive sports. A retrospective study was conducted on the data coming from surveillance carried out during the pre-participation screening of sports eligibility. These data came from the regional reference center for Sports Medicine of the Tuscany Region, Italy in the period of 1 January 1998 to 31 October 2018, inclusively.

\subsection{Study Population}

We analyzed the data from 8307 young athletes ( 5578 males and 2729 females) aged between 6 and 18 years (mean age $13.9 \pm 2.2$ years). Inclusion criteria for the subjects were: Caucasian, practice sports at a competitive level, and not to have any contraindications to sports eligibility. Exclusion criteria in the analyses were having already carried out the same visit and being already included in the study sample at a lower age, having received a temporary suspension of sports eligibility, having received indications for further clinical and/or instrumental evaluations, having received sports eligibility for less than 12 months and an age outside the range of \pm 6 months compared to the average age of its own stratum.

The study was carried out in conformity with the ethical standards laid down in the 1975 Declaration of Helsinki. This study is part of a project of the Tuscany Region called "Sports Medicine to support regional surveillance systems". It was approved in the Regional Prevention Plan 2014-2018 with the number O-Range18. All data were processed anonymously. 


\subsection{Clinical Evaluation}

The procedures of clinical evaluation were in accordance with the Italian protocol [20], which includes family and personal history, physical examination, and finally cardiological evaluation.

The physical examination also included the measurement of height and weight by trained personnel, using appropriate equipment (Seca GmbH \& Co., Hamburg, Germany). BMI was calculated using the formula weight $/$ height $^{2}\left(\mathrm{~kg} / \mathrm{m}^{2}\right)$. In order to define normal weight (NW) and overweight/obese status (O\&O), a subdivision according to BMI, age, and sex was adopted following the classification based on the International Obesity Task Force (IOTF) for children and adolescent [21].

Cardiological evaluation consisted of a 12-lead electrocardiogram (ECG) at rest and during a GXT. Appropriate-sized and adjustable equipment was used to meet the demands of the pediatric age. Both sexes performed GXT on treadmills or cycle ergometer. The GXT was performed by increasing the speed and/or the grade of the treadmill or by increasing the work on the cycle ergometer with the same pedaling frequency. In particular, Bruce modified protocol for the treadmill and an increase of $25 \mathrm{~W}$ every $3 \mathrm{~min}$ with a pedaling frequency of $70 \mathrm{rpm}$ for the cycle ergometer were adopted [4] with up to $85 \%$ of age-predicted maximal HR [20].

Sport eligibility certification is 1 year and generally it does not coincide with the beginning of the competitive season. Therefore, the evaluations were performed during the regular season.

\subsection{Variables}

The variables used in this study derive from the clinical evaluation for eligibility in competitive sports. Those resulting from the physical exam are gender, age, height, weight, BMI, weight status (NW or O\&O), resting HR and resting BP. Those resulting from the GXT are the number of completed stages, HR at the interruption of the test (HR max), HR after 4 min post-test (HR rec), systolic and diastolic BP at the end of the test (SBP max, DBP max), and the systolic and diastolic BP after 4 min post-test (SBP rec, DBP rec). In order to evaluate the magnitude of increase and decrease during and after the GXT, the differences between resting, maximum, and recovery values were calculated for heart rate, systolic and diastolic blood pressure ( $\Delta \mathrm{HR}$ max-rest, $\Delta \mathrm{HR}$ max-rec, $\Delta \mathrm{SBP}$ max-rest, $\Delta \mathrm{SBP}$ max-rec, $\triangle$ DBP max-rest, $\triangle$ DBP max-rec).

\subsection{Statistical Analysis}

The Mann-Whitney test was used to analyze independent and non-normally distributed continuous variables (deviation from Gaussian distribution was checked by using the Shapiro-Wilks test); data, for simplicity, are shown as mean \pm SD. All statistical analyses were performed using IBM-SPSS@version 25.0 (IBM Corp., Armonk, NY, USA, 2017). In all analyses, a two-sided $p$-value $\leq 0.05$ was considered significant.

\section{Results}

Starting from 8307 subjects that were included in the study, 3075 males and 1299 females carried out the cycle ergometer GXT and 2503 males and 1430 females carried out the treadmill GXT. The prevalence of overweight and obesity in the whole sample was $13.4 \%$ (14.7\% of males and $10.8 \%$ of females).

In the whole group, the excess weight condition led to higher resting $\mathrm{HR}(\mathrm{NW}=84.2 \pm 14.2$; $\mathrm{O} \& \mathrm{O}=86.9 \pm 14.4 \mathrm{bpm} ; p<0.001), \mathrm{SBP}(\mathrm{NW}=102.2 \pm 11.6 ; \mathrm{O} \& \mathrm{O}=106.2 \pm 12.7 \mathrm{bpm} ; p<0.001)$, and $\mathrm{DBP}$ values $(\mathrm{NW}=63.9 \pm 8.3 ; \mathrm{O} \& \mathrm{O}=66.3 \pm 8.3 ; p<0.001)$.

On average, the O\&O subjects managed to perform fewer stages during the GXT (Table 1 . This occurs mainly on the tests performed on the treadmill ( $\mathrm{NW}=7.8 \pm 1.0, \mathrm{O} \& \mathrm{O}=7.4 \pm 1.0 ; p<0.001$ ) and in males ( $\mathrm{NW}=7.6 \pm 1.5, \mathrm{O} \& \mathrm{O}=7.3 \pm 1.4 ; p<0.001)$. No differences were found in the maximum HR values, not even based on the sex and type of exercise performed (Figures 1 and 2). 
Table 1. Differences in $\triangle \mathrm{HR}$ and in $\triangle \mathrm{BP}$ performances according to weight status, gender, and type of exercise performed.

\begin{tabular}{|c|c|c|c|c|c|c|c|c|c|c|}
\hline & & $\begin{array}{c}\text { Age } \\
\text { (years.) }\end{array}$ & $\begin{array}{c}\text { BMI } \\
\left(\mathrm{kg} / \mathrm{m}^{2}\right)\end{array}$ & n. stages & $\begin{array}{c}\Delta \text { HR max-rest } \\
(\mathrm{bpm})\end{array}$ & $\begin{array}{c}\Delta \text { HR max-rec } \\
(\mathrm{bpm})\end{array}$ & $\begin{array}{c}\Delta \text { SBP max-rest } \\
(\mathrm{mmHg})\end{array}$ & $\begin{array}{c}\Delta \text { DBP max-rest } \\
(\mathrm{mmHg})\end{array}$ & $\begin{array}{l}\Delta \text { SBP max-rec. } \\
(\mathrm{mmHg})\end{array}$ & $\begin{array}{c}\Delta \text { DBP max-rec. } \\
\text { (mmHg) }\end{array}$ \\
\hline \multirow{2}{*}{ Whole Group } & NW (7190) & $14.0 \pm 2.2$ & $19.1 \pm 2.2 * *$ & $7.2 \pm 1.5 * *$ & $95.3 \pm 13.8^{* *}$ & $78.1 \pm 13.1^{*}$ & $34.6 \pm 14.7 *$ & $10.4 \pm 8.7$ ** & $28.5 \pm 13.1^{*}$ & $5.9 \pm 8.0$ \\
\hline & O\&O (1117) & $13.5 \pm 2.2$ & $24.3 \pm 2.7$ & $7.1 \pm 1.4$ & $92.9 \pm 13.4$ & $77.3 \pm 12.1$ & $35.8 \pm 15.7$ & $11.5 \pm 8.7$ & $29.5 \pm 13.9$ & $6.4 \pm 7.8$ \\
\hline \multirow{2}{*}{ Males } & NW (4758) & $14.2 \pm 2.2$ & $19.3 \pm 2.2 * *$ & $7.6 \pm 1.5 * *$ & $97.3 \pm 13.4^{* *}$ & $78.9 \pm 12.9 *$ & $36.5 \pm 15.2 *$ & $11.0 \pm 8.9 *$ & $30.1 \pm 13.6$ & $6.2 \pm 8.0$ \\
\hline & O\&O (820) & $13.7 \pm 2.1$ & $24.4 \pm 2.8$ & $7.3 \pm 1.4$ & $94.5 \pm 12.8$ & $77.7 \pm 12.2$ & $37.9 \pm 16.3$ & $11.9 \pm 8.9$ & $31.1 \pm 13.7$ & $6.5 \pm 7.9$ \\
\hline \multirow{2}{*}{ Females } & NW (2431) & $13.7 \pm 2.2$ & $18.8 \pm 2.2 * *$ & $6.5 \pm 1.3$ & $91.3 \pm 13.8^{*}$ & $76.5 \pm 13.3$ & $30.7 \pm 12.7$ * & $9.1 \pm 8.2$ & $25.4 \pm 11.4$ & $5.3 \pm 7.8$ \\
\hline & O\&O (298) & $12.8 \pm 2.3$ & $24.0 \pm 2.6$ & $6.4 \pm 1.2$ & $88.5 \pm 14.1$ & $76.1 \pm 11.7$ & $29.7 \pm 12.2$ & $10.6 \pm 8.0$ & $25.0 \pm 13.4$ & $6.1 \pm 7.6$ \\
\hline \multirow{2}{*}{ Cycle } & NW (3814) & $14.3 \pm 2.2$ & $19.4 \pm 2.1 * *$ & $6.8 \pm 1.7$ & $97.0 \pm 13.8 * *$ & $77.2 \pm 13.2 *$ & $38.1 \pm 15.5 *$ & $10.8 \pm 9.0$ & $30.5 \pm 13.9 *$ & $5.0 \pm 8.0$ \\
\hline & $\mathrm{O} \& \mathrm{O}(560)$ & $13.8 \pm 2.1$ & $24.5 \pm 2.7$ & $6.8 \pm 1.7$ & $94.2 \pm 13.2$ & $76.1 \pm 12.1$ & $39.6 \pm 17.1$ & $11.5 \pm 8.9$ & $31.9 \pm 14.4$ & $5.2 \pm 7.8$ \\
\hline \multirow{2}{*}{ Treadmill } & NW (3377) & $13.7 \pm 2.4$ & $18.9 \pm 2.3 * *$ & $7.8 \pm 1.0^{* *}$ & $93.3 \pm 13.5$ * & $79.1 \pm 12.9$ & $30.6 \pm 12.6^{*}$ & $9.8 \pm 8.4 * *$ & $26.2 \pm 11.7$ & $7.0 \pm 7.8$ \\
\hline & O\&O (556) & $13.2 \pm 2.3$ & $24.1 \pm 2.7$ & $7.4 \pm 1.0$ & $91.7 \pm 13.6$ & $78.5 \pm 12.0$ & $31.9 \pm 13.1$ & $11.5 \pm 8.5$ & $27.1 \pm 13.0$ & $7.6 \pm 7.7$ \\
\hline
\end{tabular}

Legend: HR: heart rate; BP: blood pressure; NW: normal weight; O\&O: overweight and obese; SBP: systolic blood pressure; DBP: diastolic blood pressure. ${ }^{*} p<0.05$ between normal

weight and overweight and obese subjects, ${ }^{* *} p<0.001$ between normal weight and overweight and obese subjects. In parentheses, the number of subjects referred to the group. 


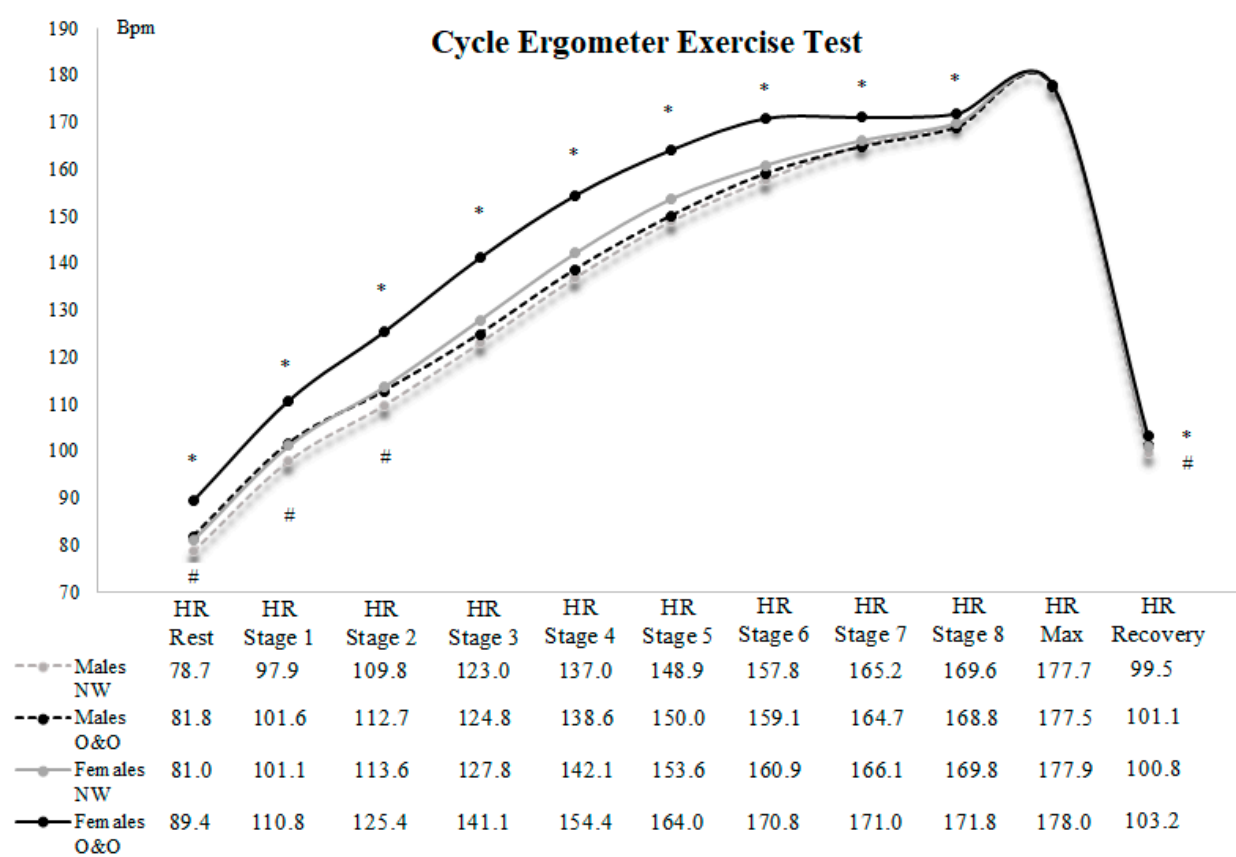

Figure 1. Differences in HR performances during cycle ergometer graded exercise test (GXT) according to weight status and gender. Legend: HR: heart rate, NW: normal weight; O\&O: overweight and obese. $* p<0.05$ between normal weight vs. overweight and obese females, $\# p<0.05$ between normal weight vs. overweight and obese males.

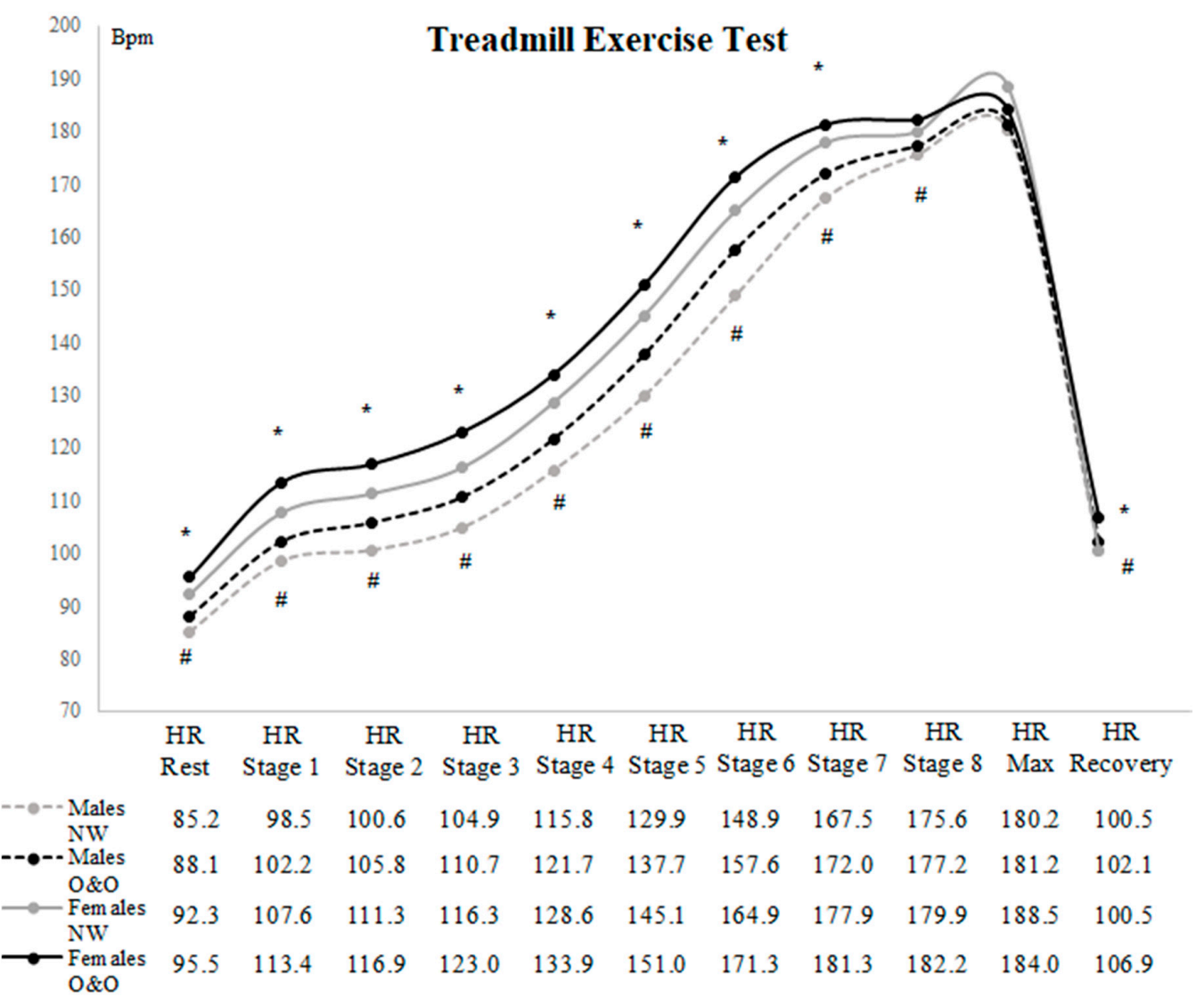

Figure 2. Differences in HR performances during treadmill GXT according to weight status and gender. Legend: HR: heart rate, NW: normal weight; O\&O: overweight and obese. ${ }^{*} p<0.05$ between normal weight vs. overweight and obese females, \# $p<0.05$ between normal weight vs. overweight and obese males. 
SBP values reached at the end of the test were higher in $\mathrm{O} \& \mathrm{O}$ subjects $(\mathrm{NW}=136.7 \pm 18.8 ; \mathrm{O} \& \mathrm{O}=$ $141.9 \pm 20.2 \mathrm{mmHg} ; p<0.001$; Figures 3 and 4$)$. The maximum DBP was on average higher in the O\&O $(\mathrm{NW}=53.5 \pm 8.0 ; \mathrm{O} \& \mathrm{O}=54.7 \pm 8.2 \mathrm{mmHg} ; p<0.001)$; however, this difference disappeared by taking the test on the treadmill $(\mathrm{NW}=53.7 \pm 7.9, \mathrm{O} \& \mathrm{O}=54.3 \pm 8.2 \mathrm{mmHg} ; p>0.05 ;=\mathrm{NS}$; Figure 4$)$.

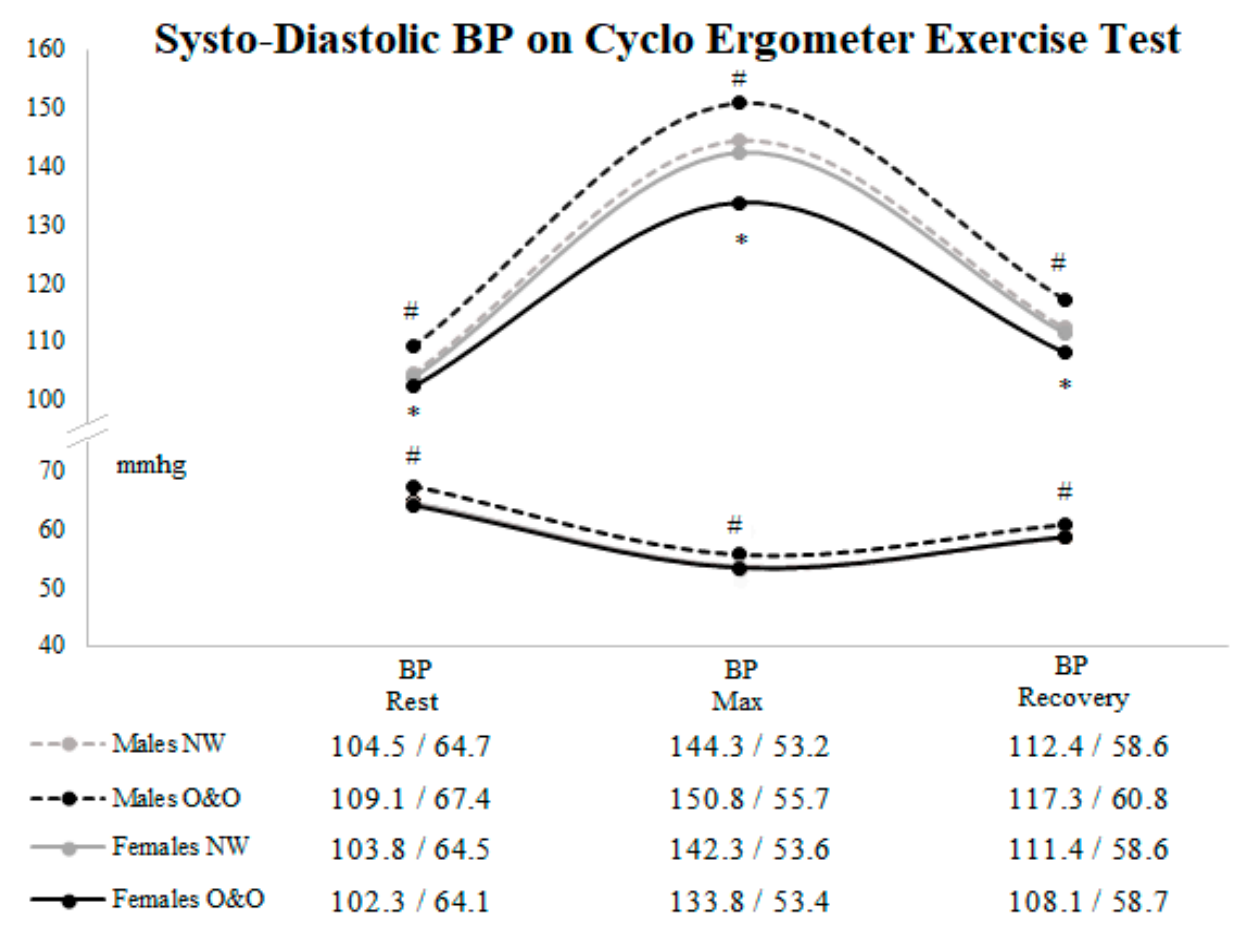

Figure 3. Differences in blood pressure (BP) performances during cycle ergometer GXT according to weight status and gender. Legend: BP: blood pressure; NW: normal weight; O\&O: overweight and obese. ${ }^{*} p<0.05$ between normal weight vs. overweight and obese females, $\# p<0.05$ between normal weight vs. overweight and obese males.

After 4 min from the end of the GXT, in whole group the HR remained higher in the O\&O subjects $(\mathrm{NW}=101.4 \pm 13.1, \mathrm{O} \& \mathrm{O}=102.6 \pm 12.7 \mathrm{bpm} ; p<0.05$; Figures 1 and 2$)$. The same behavior is also described in Figures 3 and 4 for SBP $(\mathrm{NW}=108.2 \pm 13.4, \mathrm{O} \& \mathrm{O}=112.4 \pm 14.3 \mathrm{mmHg} ; p<0.001)$ and for $\mathrm{DBP}(\mathrm{NW}=59.4 \pm 7.8, \mathrm{O} \& \mathrm{O}=61.1 \pm 7.8 \mathrm{mmHg} ; p<0.001)$.

The results relating to the magnitude of the increase and decrease in HR, SBP, and DBP are shown in Table 1 . These values show a high statistical difference $(p<0.001)$ in $\Delta \mathrm{HR}$ max-rest and $\Delta$ SBP max-rest, a statistical difference $(p<0.05)$ in $\Delta \mathrm{HR}$ max-rec and $\triangle \mathrm{SBP}$ max-rec, and finally no difference in the $\triangle \mathrm{DBP}$ max-rec between athletic subjects NW and O\&O.

Figures 1 and 2 show the chronotropic increase and decrease during and after the GXT. In particular, Figure 1 shows that from the 3rd stage there are no differences in HR in male subjects who performed the cycle ergometer GXT ( NW $=123.0 \pm 18.5, \mathrm{O} \& \mathrm{O}=124.8 \pm 18.0 \mathrm{bpm} ; p=\mathrm{NS})$. Table 1 shows that on the cycle ergometer there were no differences on the number of competed stages ( $\mathrm{NW}=6.8 \pm 1.7$, $\mathrm{O} \& \mathrm{O}=6.8 \pm 1.7 \mathrm{bpm} ; p=\mathrm{NS}$ ) between NW and O\&O subjects.

Table 2 reports the results stratified by age and gender. The differences in cardiovascular parameters between NW and $\mathrm{O} \& \mathrm{O}$ appear greater in males and with increasing age. However, the differences already begin in the age group of $8-10$ years: resting BP is greater in O\&O males. From the age group 12-14 years and onwards, all parameters analyzed (except HR max) show higher values in males. In contrast, $\mathrm{O} \& \mathrm{O}$ athletic females show higher $\mathrm{BP}$ values in comparison with $\mathrm{NW}$ athletic females. 
Table 2. Differences in HR and BP performances at rest, at the maximum effort and after 4 min of recovery according to weight status, age, and gender.

\begin{tabular}{|c|c|c|c|c|c|c|c|c|c|c|c|}
\hline & & & \multicolumn{3}{|c|}{ Rest } & \multicolumn{3}{|c|}{ Maximum } & \multicolumn{3}{|c|}{ Recovery } \\
\hline & & & $\begin{array}{l}\text { HR rest } \\
(\mathrm{bpm})\end{array}$ & $\begin{array}{l}\text { SBP rest } \\
\text { (mmh) }\end{array}$ & $\begin{array}{l}\text { DBP rest } \\
\text { (mmhg) }\end{array}$ & $\begin{array}{c}\text { HR max } \\
\text { (bpm) }\end{array}$ & $\begin{array}{l}\text { SBP max } \\
\text { (mmhg) }\end{array}$ & $\begin{array}{l}\text { DBP max } \\
\text { (mmhg) }\end{array}$ & $\begin{array}{l}\text { HR rec. } \\
\text { (bpm) }\end{array}$ & $\begin{array}{l}\text { SBP rec. } \\
\text { (mmhg) }\end{array}$ & $\begin{array}{l}\text { DBP rec. } \\
\text { (mmhg) }\end{array}$ \\
\hline \multirow{4}{*}{$8-10$ years } & \multirow{2}{*}{ Males } & NW (176) & $86.4 \pm 14.2$ & $88.5 \pm 8.0 *$ & $57.2 \pm 7.0^{*}$ & $180.1 \pm 8.7$ & $116.1 \pm 14.4^{*}$ & $50.2 \pm 7.7$ & $93.7 \pm 13.3$ & $91.6 \pm 10.2 *$ & $55.3 \pm 7.2$ \\
\hline & & O\&O (32) & $89.4 \pm 13.0$ & $93.9 \pm 8.3$ & $60.3 \pm 5.7$ & $180.7 \pm 6.9$ & $122.7 \pm 14.2$ & $50.9 \pm 8.6$ & $93.9 \pm 12.5$ & $95.9 \pm 9.5$ & $55.8 \pm 8.2$ \\
\hline & \multirow{2}{*}{ Females } & NW (145) & $95.3 \pm 13.0$ & $89.7 \pm 9.0$ & $57.2 \pm 7.8^{*}$ & $183.2 \pm 7.6$ & $113.3 \pm 11.3$ & $49.8 \pm 8.0$ & $100.9 \pm 11.5$ & $91.0 \pm 9.7^{*}$ & $54.8 \pm 6.5$ \\
\hline & & $\mathrm{O} \& \mathrm{O}(42)$ & $94.8 \pm 12.5$ & $92.0 \pm 9.9$ & $60.4 \pm 7.1$ & $184.9 \pm 6.8$ & $117.5 \pm 15.0$ & $51.7 \pm 7.4$ & $102.7 \pm 15.6$ & $95.4 \pm 9.8$ & $56.4 \pm 5.4$ \\
\hline \multirow{4}{*}{ 10-12 years } & \multirow{2}{*}{ Males } & NW (488) & $85.6 \pm 12.7$ & $94.8 \pm 8.7^{* *}$ & $59.8 \pm 7.3^{* *}$ & $180.9 \pm 7.0$ & $124.6 \pm 14.4^{* *}$ & $52.1 \pm 7.7$ & $96.3 \pm 13.1^{*}$ & $98.8 \pm 10.0 * *$ & $57.5 \pm 7.3 *$ \\
\hline & & O\&O (108) & $88.4 \pm 13.6$ & $100.1 \pm 10.3$ & $63.1 \pm 6.9$ & $181.3 \pm 8.5$ & $132.1 \pm 15.0$ & $53.1 \pm 6.9$ & $99.7 \pm 13.6$ & $105.3 \pm 10.4$ & $59.4 \pm 6.3$ \\
\hline & \multirow{2}{*}{ Females } & NW (415) & $92.5 \pm 14.1$ & $94.1 \pm 9.0 * *$ & $59.2 \pm 6.8 * *$ & $183.1 \pm 7.1$ & $121.8 \pm 13.1$ & $51.1 \pm 7.5$ & $104.2 \pm 15.0$ & $97.3 \pm 9.7 *$ & $56.8 \pm 7.1$ * \\
\hline & & $\mathrm{O} \& \mathrm{O}(62)$ & $95.4 \pm 13.3$ & $99.8 \pm 11.7$ & $63.9 \pm 7.5$ & $183.8 \pm 8.6$ & $124.4 \pm 15.3$ & $51.5 \pm 7.0$ & $105.1 \pm 12.2$ & $103.5 \pm 16.6$ & $59.8 \pm 7.4$ \\
\hline \multirow{4}{*}{ 12-14 years } & \multirow{2}{*}{ Males } & NW (1406) & $83.9 \pm 13.2 * *$ & $99.7 \pm 10.3 * *$ & $62.1 \pm 7.7^{* *}$ & $180.1 \pm 7.5$ & 133. $5 \pm 16.1 * *$ & $54.4 \pm 8.4 * *$ & $99.3 \pm 12.7^{*}$ & $105.8 \pm 11.9 * *$ & $58.2 \pm 7.1 * *$ \\
\hline & & $\mathrm{O} \& \mathrm{O}(294)$ & $87.1 \pm 12.4$ & $105.2 \pm 12.4$ & $65.6 \pm 7.9$ & $180.3 \pm 7.6$ & $139.9 \pm 16.7$ & $52.1 \pm 7.8$ & $101.5 \pm 12.4$ & $110.9 \pm 12.1$ & $60.6 \pm 7.8$ \\
\hline & \multirow{2}{*}{ Females } & NW (758) & $92.0 \pm 14.3^{*}$ & $99.4 \pm 9.8^{* *}$ & $62.5 \pm 7.2 *$ & $181.1 \pm 7.1$ & $130.6 \pm 14.7^{* *}$ & $53.2 \pm 7.4$ & $104.6 \pm 13.6$ & $104.9 \pm 10.9 * *$ & $58.7 \pm 7.6 *$ \\
\hline & & O\&O (98) & $94.5 \pm 14.0$ & $103.7 \pm 10.6$ & $64.4 \pm 7.7$ & $181.6 \pm 6.9$ & $134.9 \pm 12.4$ & $54.2 \pm 6.9$ & $106.7 \pm 12.5$ & $107.9 \pm 10.7$ & $60.9 \pm 6.3$ \\
\hline \multirow{3}{*}{$14-16$ years } & \multirow{2}{*}{ Males } & NW (1555) & $80.2 \pm 13.0^{*}$ & $107.0 \pm 10.6$ ** & $66.2 \pm 8.1^{* *}$ & $178.5 \pm 8.1$ & $145.4 \pm 16.8^{* *}$ & $54.2 \pm 8.1 * *$ & $101.4 \pm 12.7^{*}$ & $113.9 \pm 11.8^{* *}$ & $60.4 \pm 7.9^{* *}$ \\
\hline & & $\mathrm{O} \& \mathrm{O}(249)$ & $82.1 \pm 14.5$ & $112.2 \pm 10.8$ & $69.0 \pm 8.2$ & $178.4 \pm 7.6$ & $153.5 \pm 17.4$ & $56.1 \pm 8.7$ & $103.1 \pm 12.7$ & $120.4 \pm 12.0$ & $62.3 \pm 7.7$ \\
\hline & Females & $\mathrm{O} \& \mathrm{O}(68)$ & $88.0 \pm 15.0$ & $106.5 \pm 12.2$ & $67.0 \pm 8.4$ & $179.3 \pm 6.3$ & $139.0 \pm 15.9$ & $56.7 \pm 7.7$ & $105.1 \pm 12.5$ & $112.3 \pm 13.0$ & $61.0 \pm 8.7$ \\
\hline \multirow{4}{*}{$16-18$ years } & \multirow{2}{*}{ Males } & NW (1133) & $77.5 \pm 13.0^{*}$ & $110.1 \pm 10.7^{* *}$ & $68.5 \pm 7.7$ & $176.5 \pm 6.1$ & $151.6 \pm 18.1 * *$ & $55.5 \pm 8.4^{*}$ & $101.2 \pm 12.5^{*}$ & $118.1 \pm 11.9 * *$ & $62.4 \pm 8.2 * *$ \\
\hline & & $\mathrm{O} \& \mathrm{O}(137)$ & $81.0 \pm 14.5$ & $114.1 \pm 11.2$ & $70.5 \pm 8.2$ & $176.5 \pm 7.3$ & $159.6 \pm 20.9$ & $57.2 \pm 8.6$ & $103.1 \pm 11.2$ & $123.3 \pm 12.7$ & $65.1 \pm 7.9$ \\
\hline & \multirow{2}{*}{ Females } & NW (425) & $86.2 \pm 14.3$ & $102.2 \pm 10.5$ & $65.2 \pm 7.7^{*}$ & $178.4 \pm 6.3$ & $135.5 \pm 15.5^{*}$ & $55.6 \pm 5.6$ & $107.9 \pm 13.0$ & $108.8 \pm 12.8^{*}$ & $60.2 \pm 8.4$ \\
\hline & & $\mathrm{O} \& \mathrm{O}(26)$ & $89.5 \pm 16.8$ & $105.4 \pm 12.2$ & $67.4 \pm 6.3$ & $177.0 \pm 7.3$ & $139.4 \pm 15.9$ & $55.6 \pm 7.7$ & $103.9 \pm 13.1$ & $112.7 \pm 11.8$ & $60.8 \pm 7.6$ \\
\hline
\end{tabular}

Legend: HR: heart rate; BP: blood pressure; NW: normal weight; O\&O: overweight and obese. ${ }^{*} p<0.05$ between normal weight and overweight and obese subjects, ${ }^{* *} p<0.001$ between normal weight and overweight and obese subjects. In parentheses, the number of subjects referred to the group 


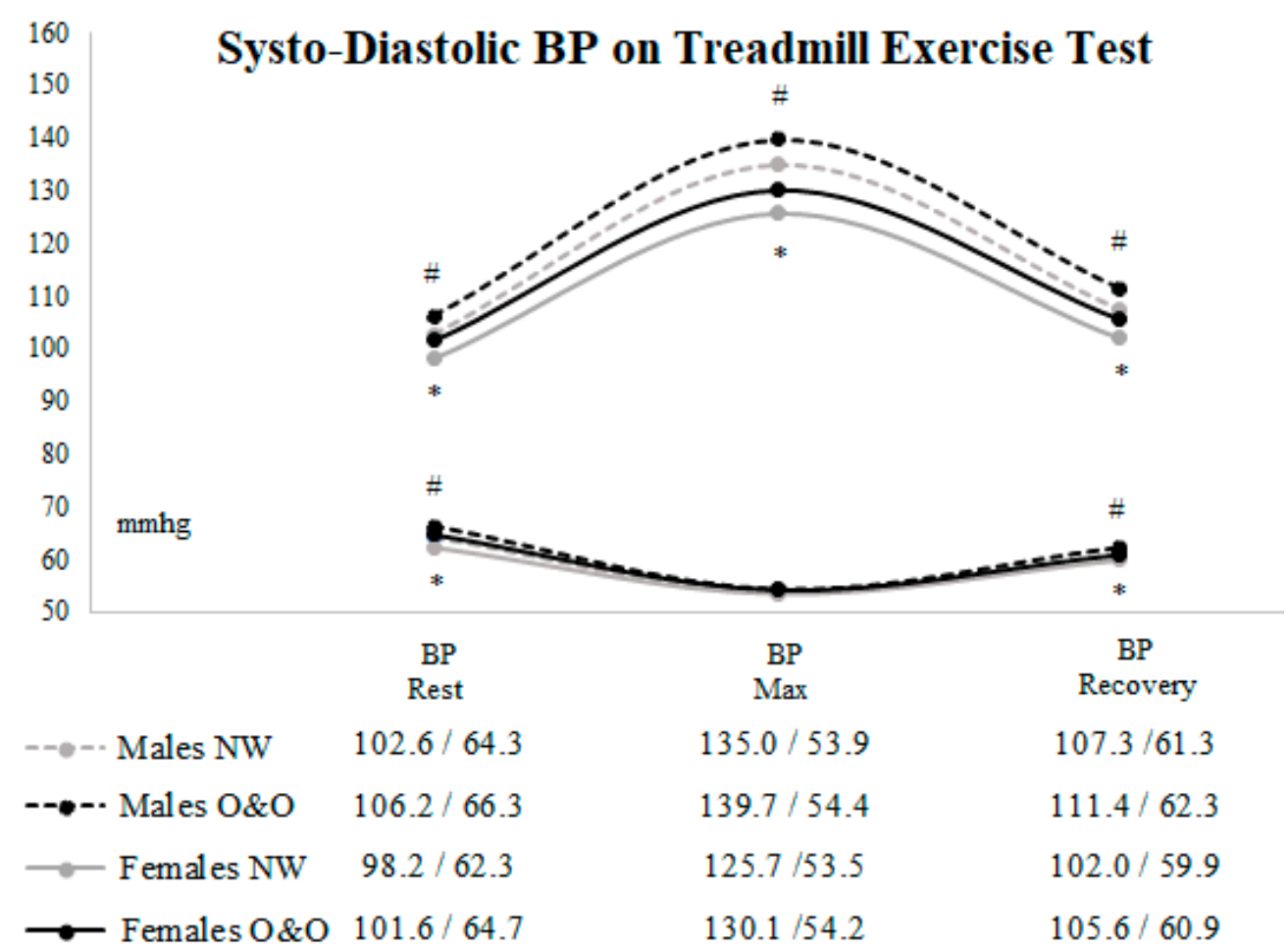

Figure 4. Differences in blood pressure (BP) performances during treadmill GXT according to weight status and gender. Legend: BP: blood pressure; NW: normal weight; O\&O: overweight and obese. ${ }^{*} p<0.05$ between normal weight vs. overweight and obese females, $\# p<0.05$ between normal weight vs. overweight and obese males.

\section{Discussion}

The objective of this study was to describe the impact of excess weight on the cardiovascular parameters in young athletes; therefore, heart rate and blood pressure values resulting from a GXT were analyzed. Although the results of the present study were within normal range, they demonstrate how excess weight affects the cardiovascular parameters recorded both at rest and during physical exertion, even in young, healthy, and sporty people [22].

Epidemiologically, the prevalence of overweight and obesity is in agreement with previous studies carried out on young athletic subjects of the same territory [23-25].

Unlike previous studies [3], HR max was the only parameter not affected, both by analyzing the sample based on gender and the type of exercise performed. However, Italian guidelines declare that the achievement of $85 \%$ of age-predicted maximal HR is a main criterion to define a sufficient effort during GXT and generally, it is used in combination with other parameters to terminate the evaluation [20]. Although HR max shows no differences between the NW and O\&O subjects, the magnitude of increase or decrease, studied with $\Delta \mathrm{HR}$ max-rest and $\Delta \mathrm{HR}$ max-rec, is influenced by the parameters of HR rest and HR recovery, both greater in subjects with excess weight [12]. In particular, the differences between NW and $\mathrm{O} \& \mathrm{O}$ in $\mathrm{HR}$ at rest start from the age group of 12-14 years in the male group. This confirms the results of previous studies conducted on non-sports subjects [26]; however, the HR rest of non-athletic obese children appears higher than the results obtained from $\mathrm{O} \& \mathrm{O}$ subjects of the present study conducted on a sample of young athletic subjects. The differences between NW and $\mathrm{O} \& \mathrm{O}$ in HR recovery also begin in the male group but already from 10-12 years. The comparison in HR recovery between the values of the sports subjects recorded after 4 min with those of the non-sports subjects recorded after $6 \mathrm{~min}$ from the end of the GXT describe a better performance in young athletes on average of $5 \mathrm{bpm}$ for the subjects NW than for O\&O [26]. Therefore, it is possible to speculate that sports practice can improve HR at rest and the recovery process after physical effort also in excess body weight condition. Furthermore, the differences in HR between NW and O\&O can 
be shown early through physical exertion. In fact, the GXT results show these differences in a previous age group compared to those shown in resting conditions.

The parameter that appears most influenced by excess weight is the SBP, which undergoes an increase both in resting values, at the peak of the effort and after $4 \mathrm{~min}$ from the interruption of the GXT, probably due to a greater cardiac output in the O\&O subjects [17]. As reported by previous studies [14], our results also show that older athletes have a lower SBP max value than younger ones. The physiological response of SBP during dynamic exercise usually involves an increase from 50 to $70 \mathrm{mmHg}$ in young people whether they are normotensive or hypertensive [27]; however, $\triangle \mathrm{SBP}$ max-rest shows data around $30-40 \mathrm{mmHg}$, with higher values in the exercise performed by the females and with cycle ergometer. This lower $\Delta$ SBP max-rest value obtained by young athletic subjects suggests a better relationship between cardiac output and the response of the vascular endothelium. The analysis of the $\triangle$ SBP max-rec results show less significant differences, therefore the SBP has slightly higher values but the effort in excess weight conditions has a reduced effect on the recovery of blood pressure in young athletes.

There is currently no behavior recognized as physiological in DBP's response to exercise; some published studies have shown a decrease in DBP, whereas others have reported no change in the levels observed at rest and a few have noted an increase in DBP $[10,28]$. Our DBP results shows a decrease behavior of about $10 \mathrm{mmHg}$ upon reaching the peak of the exercise. Excess weight affects resting values in both sexes, while the values related to effort are mainly higher in males from 12 years old. In particular, the analysis of $\triangle \mathrm{DBP}$ does not seem to add information in this context.

Body weight influences physical performance [26,29]; the results relating to the number of completed stages show lower values in O\&O subjects. A condition that appears to reduce this behavior is the use of the cycle ergometer. This is probably because in young athletes, where there is no state of physical deconditioning, the support that the tool exerts on weight is somehow useful, avoiding any direct gravity action of the body on the ground.

The use of the cycle ergometer also promotes the reduction of the differences between NW and $\mathrm{O} \& \mathrm{O}$ in $\mathrm{DBP}$ values in females at the maximum effort and during recovery. However, it appears more effective in reducing chronotropic increase differences in males. No difference, in fact, was registered from the third stage, probably because of the body weight support action.

The present study shows strengths. First, the subjects were different from each other, they all belonged to the same center, and the evaluation methodology was standardized. The second is the homogeneity of the sample, all young people practiced organized sports at a competitive level.

The study has the limitation of being retrospective; this influences causality because the registered weight status is established in advance of the exercise test day. In addition, the study defines the weight status through the BMI: this method has the intrinsic limitation in distinguishing an overweight condition due to an excess of body fat from that due to a prevalence of muscle tissue. However, the authors chose this study design and the use of BMI in order to achieve this sample size with the homogeneity between the subjects described above.

This study did not distinguish children and adolescents by maturity stage; it could be inferred that the heterogeneity of the sample could alter the accuracy of the results. However, the objective of the study does not foresee the evaluation following growth phases, since this aspect involves an additional variable that would not allow the evaluation carried out on such a large sample [30].

\section{Conclusions}

Excess weight affects cardiovascular parameters both at rest and in response to physical exertion during youth. The cardiovascular parameters analyzed in the present study are heart rate and blood pressure: the effect that excess weight has on these parameters increases with the progress of growth.

The parameters that could help provide further information seem to be the differences $(\Delta)$ between rest and peak of effort and between peak of effort and after 4 min of recovery. 
However, competitive sports seem to be able to keep these parameters within the normal range even in young overweight athletic subjects. This once again highlights the effectiveness of youth from a public health perspective.

Author Contributions: Conceptualization, G.M. and C.P.; methodology, G.M.; software, V.B.; formal analysis, V.B.; investigation, G.M., L.S., and L.T.; data curation, G.M.; writing-original draft preparation, G.M.; supervision, G.G.; project administration, P.C. All authors have read and agreed to the published version of the manuscript.

Funding: This research received no external funding.

Conflicts of Interest: The authors declare no conflicts of interest.

\section{References}

1. WHO. Obesity Fact Sheet. Available online: https://www.who.int/news-room/fact-sheets/detail/obesity-andoverweight (accessed on 5 March 2020).

2. Martini, G.; Riva, P.; Rabbia, F.; Molini, V.; Ferrero, G.B.; Cerutti, F.; Carra, R.; Veglio, F. Heart rate variability in childhood obesity. Clin. Auton. Res. 2001, 11, 87-91. [CrossRef] [PubMed]

3. Török, K.; Szelényi, Z.; Pórszász, J.; Molnár, D. Low physical performance in obese adolescent boys with metabolic syndrome. Int. J. Obes. Relat. Metab. Disord. 2001, 25, 966-970. [CrossRef] [PubMed]

4. Fletcher, G.F.; Ades, P.A.; Kligfield, P.; Arena, R.; Balady, G.J;; Bittner, V.; Coke, L.A.; Fleg, J.L.; Forman, D.E.; Gerber, T.C.; et al. Exercise standards for testing and training: A scientific statement from the American Heart Association. Circulation 2013, 128, 873-934. [CrossRef] [PubMed]

5. Thompson, P.D. Exercise prescription and proscription for patients with coronary artery disease. Circulation 2005, 112, 2354-2363. [CrossRef] [PubMed]

6. Pinkstaff, S.; Peberdy, M.A.; Kontos, M.C.; Finucane, S.; Arena, R. Quantifying exertion level during exercise stress testing using percentage of age-predicted maximal heart rate, rate pressure product, and perceived exertion. Mayo Clin. Proc. 2010, 85, 1095-1100. [CrossRef] [PubMed]

7. Bjelakovic, L.; Vukovic, V.; Jovic, M.; Bankovic, S.; Kostic, T.; Radovanovic, D.; Pantelić, S.; Zivkovic, M.; Stojanovic, S.; Bjelakovic, B. Heart rate recovery time in metabolically healthy and metabolically unhealthy obese children. Phys. Sportsmed. 2017, 45, 438-442. [CrossRef]

8. McArdle, W.D.; Katch, F.I.; Katch, V.L. Exercise Physiology: Nutrition, Energy, and Human Performance; Lippincott Williams \& Wilkins: Baltimore, MD, USA, 2014.

9. Syme, A.N.; Blanchard, B.E.; Guidry, M.A.; Taylor, A.W.; Vanheest, J.L.; Hasson, S.; Thompson, P.D.; Pescatello, L.S. Peak systolic blood pressure on a graded maximal exercise test and the blood pressure response to an acute bout of submaximal exercise. Am. J. Cardiol. 2006, 98, 938-943. [CrossRef]

10. Paridon, S.M.; Alpert, B.S.; Boas, S.R.; Cabrera, M.E.; Caldarera, L.L.; Daniels, S.R.; Kimball, T.R.; Knilans, T.K.; Nixon, P.A.; Rhodes, J.; et al. Clinical stress testing in the pediatric age group: A statement from the American Heart Association Council on Cardiovascular Disease in the Young, Committee on Atherosclerosis, Hypertension, and Obesity in Youth. Circulation 2006, 113, 1905-1920. [CrossRef]

11. Cooper, D.M.; Weiler-Ravell, D.; Whipp, B.J.; Wasserman, K. Growth-related changes in oxygen uptake and heart rate during progressive exercise in children. Pediatr. Res. 1984, 18, 845-851. [CrossRef]

12. Singh, T.P.; Rhodes, J.; Gauvreau, K. Determinants of heart rate recovery following exercise in children. Med. Sci. Sports Exerc. 2008, 40, 601-605. [CrossRef]

13. Easley, E.A.; Black, W.S.; Bailey, A.L.; Lennie, T.A.; Sims, W.J.; Clasey, J.L. Recovery Responses to Maximal Exercise in Healthy-Weight Children and Children with Obesity. Res. Q. Exerc. Sport 2018, 89, 38-46. [CrossRef] [PubMed]

14. Szmigielska, K.; Szmigielska-Kapłon, A.; Jegier, A. Blood pressure response to exercise in young athletes aged 10 to 18 years. Appl. Physiol. Nutr. Metab. 2016, 41, 41-48. [CrossRef] [PubMed]

15. Lintu, N.; Tompuri, T.; Viitasalo, A.; Soininen, S.; Laitinen, T.; Savonen, K.; Lindi, V.; Lakka, T.A. Cardiovascular fitness and haemodynamic responses to maximal cycle ergometer exercise test in children 6-8 years of age. $J$. Sports Sci. 2014, 32, 652-659. [CrossRef] 
16. Lintu, N.; Viitasalo, A.; Tompuri, T.; Veijalainen, A.; Hakulinen, M.; Laitinen, T.; Savonen, K.; Lakka, T.A. Cardiorespiratory fitness, respiratory function and hemodynamic responses to maximal cycle ergometer exercise test in girls and boys aged 9-11 years: The PANIC Study. Eur. J. Appl. Physiol. 2015, 115, 235-243. [CrossRef] [PubMed]

17. de Sousa, G.; Hussein, A.; Trowitzsch, E.; Andler, W.; Reinehr, T. Hemodynamic responses to exercise in obese children and adolescents before and after overweight reduction. Klin. Padiatr. 2009, 221, 237-240. [CrossRef] [PubMed]

18. Barker, A.R.; Armstrong, N. Exercise testing elite young athletes. Med. Sport Sci. 2011, 56, 106-125. [CrossRef] [PubMed]

19. Mascherini, G.; Galanti, G.; Massetti, L.; Calà, P.; Modesti, P.A. Growth Charts for Height, Weight, and BMI (6-18 y) for the Tuscany Youth Sports Population. Int. J. Environ. Res. Public Health 2019, 16, 4975. [CrossRef]

20. Biffi, A.; Delise, P.; Zeppilli, P.; Giada, F.; Pelliccia, A.; Penco, M.; Casasco, M.; Colonna, P.; D’Andrea, A.; D'Andrea, L.; et al. Italian cardiological guidelines for sports eligibility in athletes with heart disease: Part 1. J. Cardiovasc. Med. 2013, 14, 477-499. [CrossRef]

21. Cole, T.J.; Lobstein, T. Extended international (IOTF) body mass index cut-offs for thinness, overweight and obesity. Pediatr. Obes. 2012, 7, 284-294. [CrossRef]

22. Coledam, D.H.C.; Ferraiol, P.F.; Pires, R.; Júnior Greca, J.P.A.; Oliveira, A.R. Overweight and obesity are not associated to high blood pressure in young people sport practitioners. O sobrepeso e a obesidade não estão associados com a pressão arterial elevada em jovens praticantes de esportes. Ciência Saúde Coletiva 2017, 22, 4051-4060. [CrossRef]

23. Mascherini, G.; Petri, C.; Ermini, E.; Bini, V.; Calà, P.; Galanti, G.; Modesti, P.A. Overweight in Young Athletes: New Predictive Model of Overfat Condition. Int. J. Environ. Res. Public Health 2019, 16, 5128. [CrossRef] [PubMed]

24. Petri, C.; Mascherini, G.; Bini, V.; Toncelli, L.; Armentano, N.; Calà, P.; Galanti, G. Evaluation of physical activity and dietary behaviors in young athletes: A pilot study. Minerva Pediatr. 2017, 69, 463-469. [CrossRef] [PubMed]

25. Petri, C.; Mascherini, G.; Bini, V.; Anania, G.; CAL, P.; Toncelli, L.; Galanti, G. Integrated total body composition versus Body Mass Index in young athletes. Minerva Pediatr. 2016. Available online: https://www.minervamedica.it/it/riviste/minerva-pediatrica/articolo.php?cod= R15Y9999N00A16040801 (accessed on 5 March 2020).

26. Norman, A.C.; Drinkard, B.; McDuffie, J.R.; Ghorbani, S.; Yanoff, L.B.; Yanovski, J.A. Influence of excess adiposity on exercise fitness and performance in overweight children and adolescents. Pediatrics 2005, 115, e690-e696. [CrossRef]

27. Pate, R.R.; Matthews, C.; Alpert, B.S.; Strong, W.B.; DuRant, R.H. Systolic blood pressure response to exercise in black and white preadolescent and early adolescent boys. Arch. Pediatr. Adolesc. Med. 1994, 148, 1027-1031. [CrossRef]

28. Ahmad, F.; Kavey, R.E.; Kveselis, D.A.; Gaum, W.E.; Smith, F.C. Responses of non-obese white children to treadmill exercise. J. Pediatr. 2001, 139, 284-290. [CrossRef]

29. McGavock, J.M.; Torrance, B.D.; McGuire, K.A.; Wozny, P.D.; Lewanczuk, R.Z. Cardiorespiratory fitness and the risk of overweight in youth: The Healthy Hearts Longitudinal Study of Cardiometabolic Health. Obesity 2009, 17, 1802-1807. [CrossRef]

30. Campa, F.; Silva, A.M.; Iannuzzi, V.; Mascherini, G.; Benedetti, L.; Toselli, S. The Role of Somatic Maturation on Bioimpedance Patterns and Body Composition in Male Elite Youth Soccer Players. Int. J. Environ. Res. Public Health 2019, 16, 4711. [CrossRef]

(C) 2020 by the authors. Licensee MDPI, Basel, Switzerland. This article is an open access article distributed under the terms and conditions of the Creative Commons Attribution (CC BY) license (http://creativecommons.org/licenses/by/4.0/). 